\title{
MOSSES IN RELATION TO CAJANDER THEORY OF FOREST TYPES
}

\author{
by A. H. BRUNKMAN
}

$\mathbb{D}$

JRING the scasons of 1928 and 1929, the writer was employed as botanist on a party whose object was to find out whether the Cajander Theory of Forest Types was applicable to Canada.

The Moss Flora forms so dominant a part of the Forest Floor Flora of most of the forests, that they inevitably demand attention, and it is questionable how far any theory of Forest Types can be successfully applied thiat ignores them.

Cajander names one of his types the Hylocomium-Myrtillus type, making it's luxuriant moss flora it's chicf feature, while the hylocomium group centers largely into the description of others, notably his Myrtillus type and his Empetrum-Myrtillus type, so that it becomes necessary to understand the part these mosses play in the types mentioned before they can be properly understood.

The method used in 1928 was that of visual examination, counting the moss patches and nothing their distance apart, after noting the average size of the patches, noting the constituent species, and, where the moss cover was fairly continuous, a percentage was given to it.

At intervals, measured quadrats would be taken, and carefully cleared, thus enabling us to check up on the visual inspection.

As practically all the moss plant species mentioned by Ilvessalo were known to the writer in the field, there was little difficulty encountered in comparing the results found by us with those given by Ilvessalo in his very useful tables of plants and plant frequencies of the various Forest Types, though we did feel that the Norralin scale of measurements advocated and used by Cajander and Ilvessalo in their work, was not fine enough for the intensive work necessary to establish the applicability or otherwise of the Theory for use under Canadian conditions. Regarding the flowering plant constituents of the various moss types mentioned; as so many of the flowering plants mentioned by Cajander and Ilvessalo in their descriptions of the Forest Types, do not occur in Canada, or at least in the Province of Alberta, where the work was being undertaken, there was necessarily great difficulty in deciding just how the Types of Cajander were represented here. 


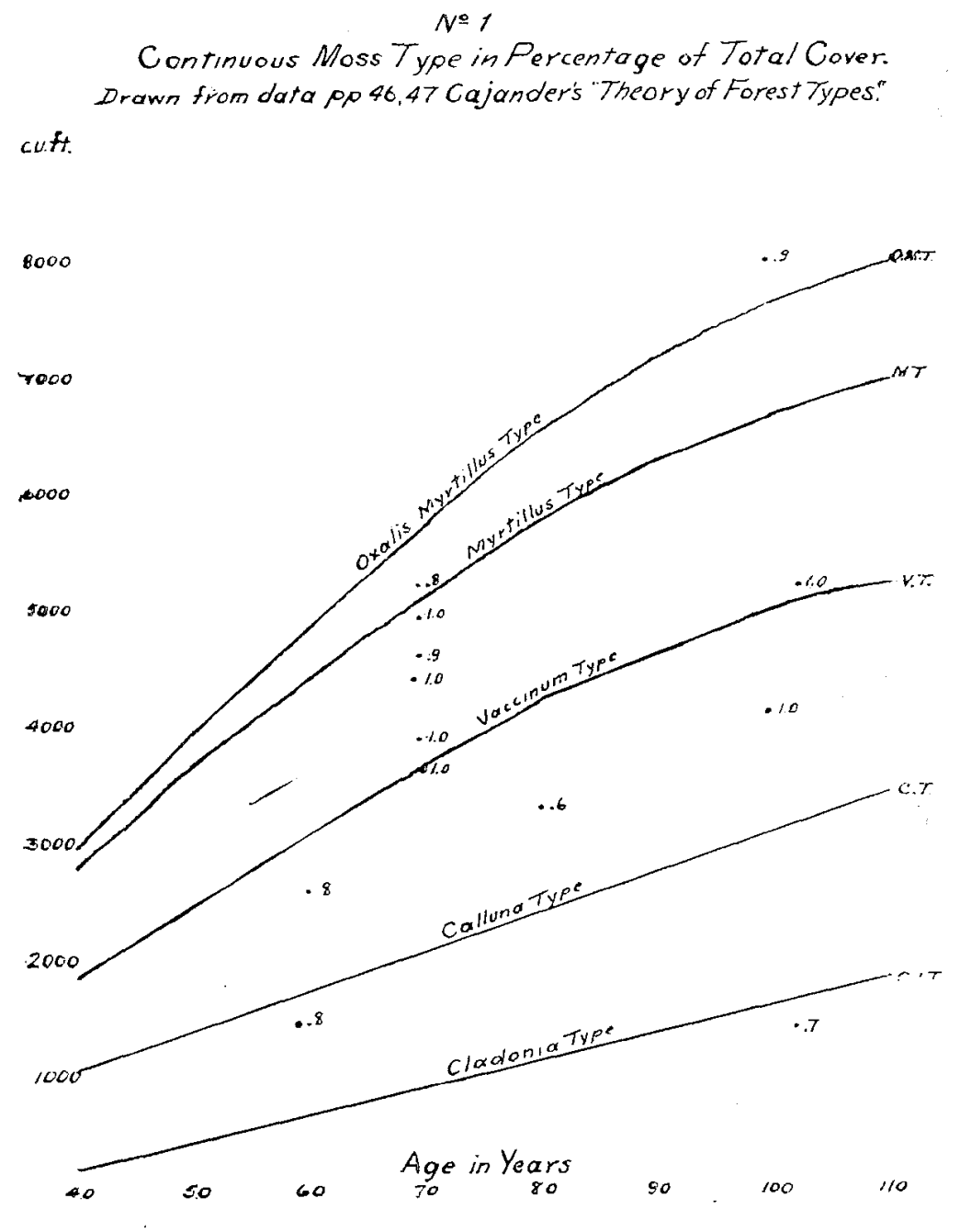

It was of no use assuming that other species of the same genera could be used in the place of the European species mentioned, even when the Genus was represented here, and the only method that seemed at all likely to give us the necessary information was that of picking out evenly stocked stands of timber in various plant associations, working up the timher volume values, and placing them in sequence, and then from the graphs thus prepared, deciding how far the different timber values were represented by different plant associations. 
The results, while not conclusive, were at least encouraging.

While they showed some plants occupying practically the whole range of timber values, it showed others having a marked preference for either the higher or lower timber value sites; this was also true of some of the mosses, with one important exception; for some of the mosses were found almost exclusively in the lower to medium timber value sites, 2 few showed a preference for the higher sites, and some ran through the whole range of sites.

The exception mentioned above was the Hylocomium group of mosses, composed of Hylocomium splendens, Hylocomium parietinum (= Hypnum Schreberi) and Ptilium crista-castrensis.

As this formed by far the largest portion of the moss flora, and was the combination chiefly concerned in the descriptions given by Cajander, we had to come to some definite conclusions about it.

As however the Hylocomium combination ran through, almost the whole range of timber values, the only conclusion that seemed safe was that the evidence was very confusing, and the whole question of moss cover required further study, to throw some new light on the matter.

A chart giving the wide range occupied by this moss combination is given, the figures being tenths, ranging from $60 \%$ to practically $100 \%$ floor covering.

The lines of the various types are worked out from the volume contents given by Cajander for Scots Pine, and is the one used by him as the basis of his work. It will be noticed that the cover extends from below the lowest to beyond the highest shown, and so had very little value as type indicators.

The lichens had already shown a tendency to fall into quality sites, if I may so term the sites with different volume values, only one plot being above the Vaccinium Type when the Lichens were common on the ground, while when the lichens were on rotten logs (mostly Cladonias outside the rangiferina group), the tendency to go into higher quality sites was quite pronounced.

This matter was more fully treated in an article in the Bryologist for September 1931, pp. 66-71.

With the Hepatics too, the same tendency to occupy different quality sites was also pronounced, some associations ( $f \circ$ r this group is very often a mixture of species) being only found on the better quality sites. In this group the evidence seemed to point to humidity being the controlling factor, with retentiveness of soils for moisture being correlated with humidity, the heavier soils showing the most humidity, the loams next, and the sandy soils least of all, and to this extent the Hepatics were an indirect reflex of the soil value of the different quality sites. This was shown to be the case in a narrow district 
with the same rainfall, but with varying soil conditions. A brief article in the, Bryologist treats this matter a little more fully, see Bryologist for Mch 1929, pp. 29-30.

The second year both the methods and the aims were different.

Having by this time a rough idea of the various plant association types to be expected, the aim was to choose the types, and work out the timber afterwards to see how far different types bore different timber values, and an examination of the soil, the different layers from Moss downwards was also part of the work undertaken.

The method used was to divide the plot into four, crosswise, with strings, and along these strings to lay out an equal number of quadrats in each quarter, at about equal distances apart, 16 in all, totalling 100 square feet. By careful counting of species, pulling out the largest plants first, and the others in sequence as we proceeded, till we came to the smallest, and the mosses. and other cryptogams, it was possible to get the correct number of each species on a definite suace on each plot.

This was followed by visual inspection over the whole plot, to take count of any specics not represented on the quadrats, and to correct any tendency the quadrats might have to overestimate, or underestimate the number of plants of the different species per measured area. By the use of a much
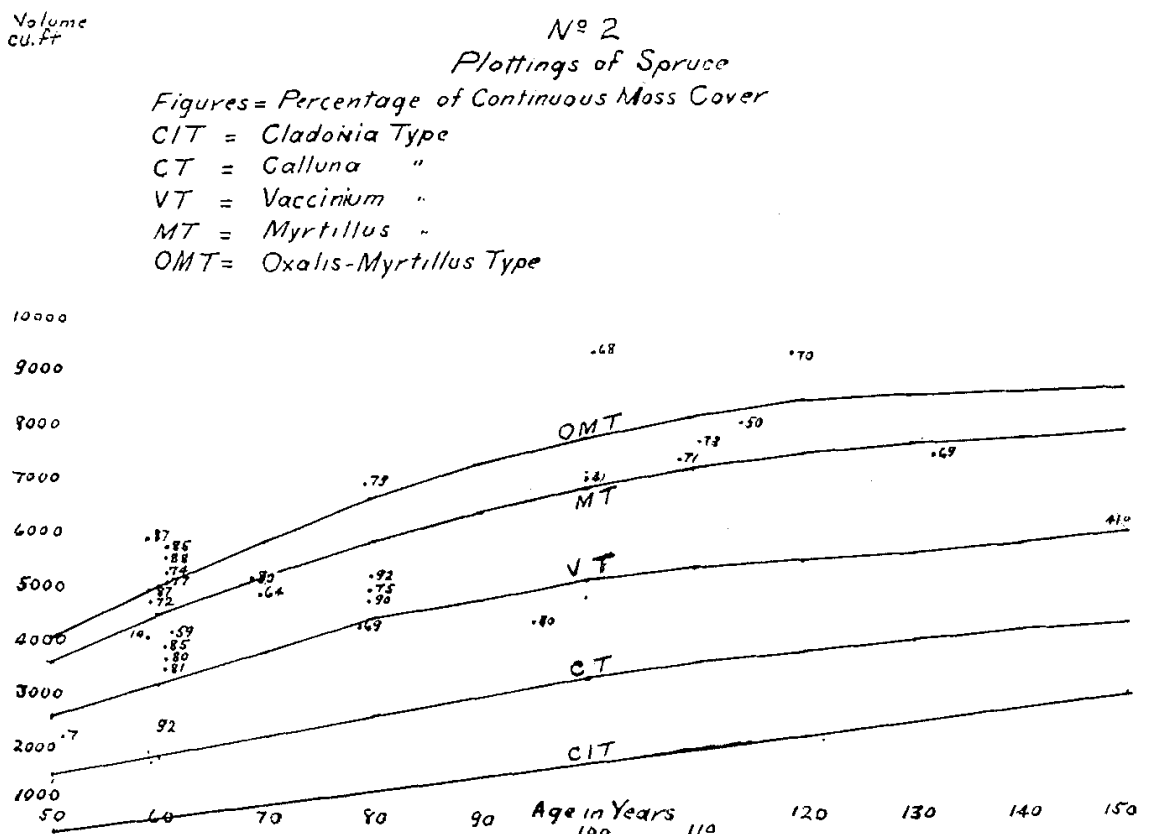
finer scale than the Norralin, it was possible to plot the results for comparative purposes so that any marked differences became readily apparent, and the relations between each fairly evident.

The scale used is a progressive one, and is given in the appendix. By treating the mosses as percentages of each quadrat covered, and taking the average of the whole number of quadrats examined, a very close approximation to the conditions over the whole plot was arrived at in the case of the Hylocomium mixture of mosses, or of any moss species or lichen association that covered more than one percent of any of the quadrats. In working over the Hylocomium group, the percentage of the constituent species of that group was given, as there seemed a tendency for Hylocomium parietinum to occupy the poorer sites, and of Ptilium to occupy the better sites. Any species not coming under the percentage basis obviously occupied less than one hundredth of the quadrat examined, and listed.

Thus our methods allowed us to follow out reasonably small differences. Remembering the perplexity that the Hylocomium group had left in our minds, close watch was kept for any indication or signs that would throw light on this perplexing question.

Very early in the season a series of plots was examined that did throw light on the continuous muss problem.

This was a series of Spruce plots on wet soils, adjoining the cut-over operations of a lumber company; part of the cut-over being of the previous year, 1927-28, part of the year before, 1926-27, part 1925-26 and part 1924-25. Five plots taken in the Spruce ranged from $41 \%$ to $70 \%$ moss cover, the moss association being present on all the quadrats examined on four plots, and on 17 of the 20 on the fifth plot.

On these plots Hylocomium splendens and Ptilium were much the most frequent species, two of the plots showing no Hylocomium parietinum. On one year cut-over, 12 quadrats showed the continuous moss type, and the mosses were in small quantity. On cut-over of 4 years standing this group of mosses had almost entirely dissappeared, showing only in small quantity on three of the quadrats; the species being Hylocomium splendens. As the cutover was decidedly wet land it could not be the factor of moisture that we were dealing with, the only factor then left being that of light, either dircctly, or possibly indirectly by controlling the matter of humidity. While the Hylocomium group of mosses had thus almost entirely dissappeared, the opposite result was noticed with the grasses. On the five Spruce plots examined the grass, Calamagrostis Canadensis averaged about a foot apart, on one year old cut-over the average was .55 feet apart, about three times as thick, on the four- 
year old cut-over the grass was so thick that it had to be taken as a percentage of covering, giving $48 \%$.

It was the continuous moss covering that had suffered, and almost disappeared, by the action of light, the other moss species showed no marked diminuation in either species or numbers.

In the two year old cut-over the Hylocomium group of mosses was obviously much less in quantity than in the adjoining uncut forest.

The only conclusions that could explain this set of facts was the letting in of light to the moss cover, or the lessening of the moisture content of the cut-over forcst site, either one or both factors.

But the cut-over forest was, as far as covild be judged on the spot, just as wet as the uncut forest, in parts super-saturated, any difference there might be was not discernable by us; apparently the spruce forest cover was taking up about as much moisture in the uncut forests, as evaporation and forest floor covering was taking up in the cut-over portions. There remained then only the factor of light, and the continuous moss cover must be dependent upon shade for it's very existence.

From this time forward continuous watch was kept for evidence bearing on this subject, and soon after, in taking field notes, density of forest cover was taken in percentages, to show what correlation, if any, existed between density and moss cover.

Other cases showing the relation between light and moss cover hegan to show up over a fairly wide district, and under varying conditions of light action.

Thus, in a Jack Pine Forest, with a valley like depression running East and West, were slopes of some 15 feet rise in the hundred feet, thus making the one side face the sun for a period longer than would have been the case on the flat, and the other side with a shorter period than the flat would have had.

The stands of timber were somewhat sinilar, both in number of trees and of timber content, having regard to the difference in age.

- The slope facing the sun, facing south, showed three percent moss cover, the slope facing the North showed $71 \%$ moss cover, and as far as could be decided on the spot, there was no marked difference in habitat, except that of different slopes to cause the difference in the moss cover.

One slope would have a much longer light day and light season that the normal on the flat, the otber would have decidedly less than normal light, and during part of the winter would have very little direct light at all. Both these plots were almost contiguous, the bottom of the valley separating them.

Another two sets show the light factor in another way.

Spruce plot 18 , moss cover $85 \%$, moss on all 16 quadrats. 
$N=3$

$\begin{array}{ll} & B=\text { Jack Pine } \\ & P=\text { Poplar } \\ \text { cuff. } & S=\text { Black Spruce } \\ & \text { Figures }=\% \text { Moss Cover }\end{array}$

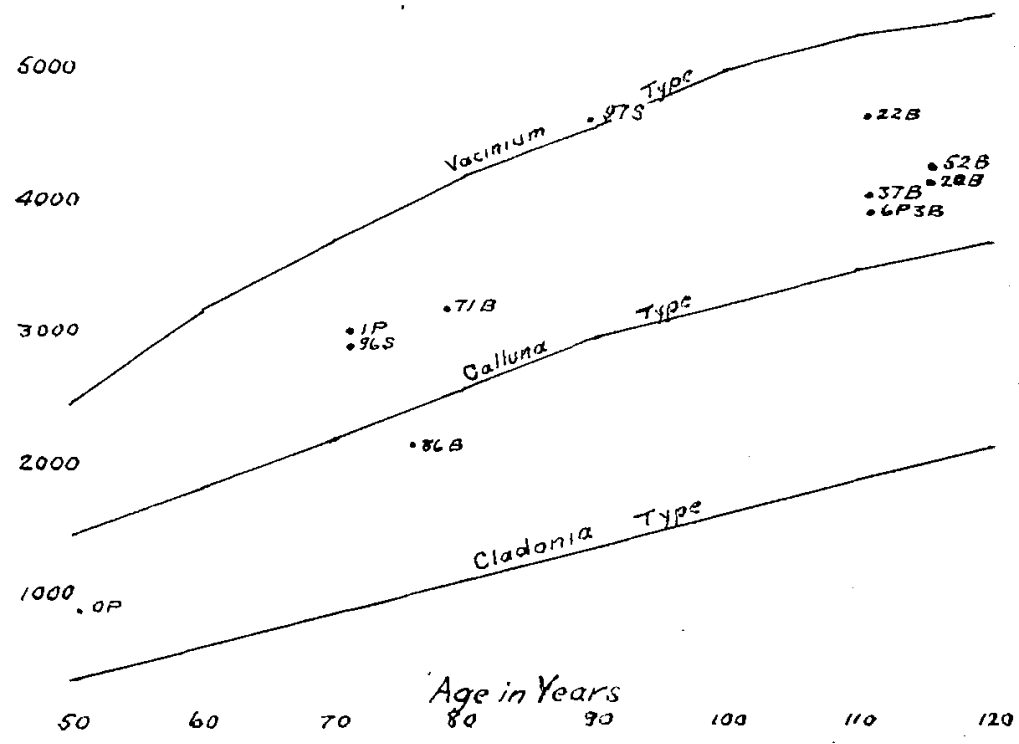

Poplar plot 2, moss cover $6 \%$ on 16 quadrats.

Both these plots were contiguous, no marked difference in habitat, excepting tree species covering plot.

Another set shows the same result.

Spruce plot 28, Moss cover $71 \%$ on 16 quadrats.

Poplar plot 8, Moss cover $8 \%$, on 7 quadrats. None on 9 quadrats.

Both these plots contiguous. 
I wish to draw attention to these two sets of plots, as they bring us face to face with another problem, that of density, and it's bearing on light and on moss cover.

It seemed a fair inference that the less the density of the forest canopy, the less should also be the percentage of moss cover, and in something like direct proportion.

But this did not work out with the Poplar Plots.

Take Spruce Plot 18, Density. 8, Moss cover $85 \%$.

Poplar Plot 2, Density .6, Moss cover 6\%.

There seemed little correlation between them.

Then take Poplar Plot 3, Density .5, moss cover 0

Poplar Plot 4, Density .6, Moss cover 1\%

Poplar Plot 5, Density .7, Moss cover 1\%

Poplar Plot 6, Density .6, Moss cover 1\%

Poplar Plot 7, Density .75, Moss cover 0.

There seemed no correlation between moss cover and density in these, and this is the more noticeable when compared with the Spruce Forest, for in similar densities of Spruce Forests, an average of well over $50 \%$ moss cover is shown.

Yet if in so many cases the continuous moss cover was a direct reflex of light conditions, there must be some explanation for this seeming anomaly. Here I think it is .

The deciduous forests (at least Poplar) do not have leaves here till from early to late May, (much depending upon the season), and on some location by the middle of September, or at most by the end of that month, the trees have lost their leaves.

During then some eigtht months there is considerable light in such forests, and very little shade. By May there is some 16 hours of sunlight daily, over most of the wooded North country, and quite a long period by the end of September.

The deciduous forests then are much open to sunlight, very much more so than the coniferous forests, and so the continuous Moss Cover cannot thrive in the deciduous forests.

Some plottings will be given showing the relation between density of canopy covering, percentage of Moss covering, and species of trees, and also showing the number of quadrats with the Moss cover on.

These plottings will tend to show that the more shade giving spruce at a Density of, say .5 will give a larger percentage of Moss cover than the Pines (Jack Pine) with their lesser shade, at the same density, and very much 
more than the Deciduous Forests at the same density. The same result of light conditions is shown in another direction, given below.

On the shore of Lesser Slave Lake a gale had uprooted quite $50 \%$ of the trees over a considerable area, the previous year.

Yet even in so short a time the cont nuous moss cover was dying, since the light had ready access to it, though where the trees were still standing the moss cover was nearly normal.

I think that sufficient evidence has been given to show that where light has ready access to the forest floor the continuous moss cover does not thrive, shows a poor growth; but that where shady conditions exist throughout the year, the moss cover thrives well.

That it is not largely concerned with moisture is shown by the cut-over plots, as the area was about equally supplied with moisture as was the neighbouring uncut Spruce Forest.

How far light alone is the determining factor, or whether heat enters in as a factor is not known. Certainly light is by far the most important factor, and moisture seems to be quite a minor factor as compared to light, judged by the evidence of the cut-over plots.

As was shown by the former sheet given, there scems little relation between site values and moss cover, as heavy percentages of moss cover occupied sites from near the lowest given to above the highest.

Two more sheets now given show the same line of facts.

Take the 31 plots of Spruce, and divide the percentages of moss cover into groups. $80 \%$ to $100 \%$ occurs on plots below V T to ahove O M T. $60 \%$ to $80 \%$ occurs on plots ranging from a little above $V \mathrm{~T}$ to well above O M T. $40 \%$ to $60 \%$ gives a range below V T to near O M T, and below $40 \%$ occurs on plots well below M. T to above O M T.

In the other sheet, that of Pines and Poplars (including 2 Black Spruce) the values for those two tree species lie from below $\mathrm{C} \mathrm{T}$ to above $\mathrm{V} T$. and the percentages of moss cover seem grouped quite indiscriminately, no sequence can be noticed.

Evidently then any attempt to use the Hylocomium mixture by itself as a site indicator would be hopeless.

Next take soil quality, and moss cover percentage.

The clays and clay loams would usually be considered high class agricultural soils. On these soils the range is from $7 \%$ to $92 \%$.

Next take the sandy loams, a variable, but fair quality agricultural soil. The moss cover on these ranges between 59 and $92 \%, 0$.

Next take the Jack Pine. Here we have a series of soils ranging from sand to sandy loam, whose timber value lies between $\mathrm{C} \mathrm{T}$ and $\mathrm{V} T$, as shown. The moss cover ranges between $71 \%$ and $3 \%$, the two extremes being treatud 
before. Other than those two, the percertage ranges between $20 \%$ and $52 \%$. $W$ ith no apparent connection between either soil and moss cover, or timber value and moss cover.

But as the Jack Pine usually occupies sandy ridges and elevated sites of a sandy nature, possibly forming a climax on such sites, it cannot fairly be compared to the Spruce sites, the more so as the very disturbing factor of fire attacks the Pine Sites more frequently, or to a greater extent than the Spruce Sites.

Here I would like to digress a little on the subject of Forest Fires, as it touches the matter of the Continuous Moss Cover.

A photo was taken showing partial burnings of a tree (Jack Pine) 129 years old in 1929, and showing quite an healthy growth then.

The fires occurred in 1932, in 1844 and in 1893. In each case the fire was severe enough to deeply scar the tree, but not severe enough to kill it. One can easily understand however that a fire severe enough to burn into the tree would he severe enough to destroy the moss cover; if wet, neither tree or moss would be burned, and if dry, both may be expected to burn. The reader will understand that the moss has then to re-establish itself anew. This factor of burning is a disturbing one throughout this district, and was constantly being met with.

While three burnings were shown above, it by no means follows that these were the only ones. Partly burned trees were constantly being met with, some showing comparatively recent burnings, and as the higher Jack Pine ridges were naturally the earliest to dry, and therefore most susceptible to burnings, it may well be that the constantly lower averages of the Moss Cover of the Jack Pine sites may be partly the result of frequent burnings and not entirely the result of the lesser shade given by the Jack Pine trees as compared to the more shade giving Spruces.

There is another possible factor concerned here, that of humidity. But that may come in another connection later.

So far then the following conclusions scen established, first:- that light is the determining factor of the Continuous Moss Cover, and second:- that the Moss Cover wanders all over the site values without any sequence as to correlation of percentage of moss cover, and of timber values and volumes.

A series of plottings is shown to bring out the relation of Moss cover to Density of Forest Canopy Cover, also as to tree species and their bearing on density and moss cover percentages.

It shows that densities of .5 can support a rich moss cover under Spruce, varying from $14 \%$ to $90 \%$, that the Jack Pine carries a lower percentage of Moss Cover under the same density.

In both cases it is known that there is no strict relationship between density of Forest Canopy and percentage of Moss cover, but the general trend is 
obvious. All the densities of .8 and above have high moss cover percentages, the lowest shown being 59\%.

It also shows that the Poplars with a similar or higher density of forest canopy cannot support a rich continuous moss cover. This is brought out before in treating of the Poplar Plots.

The Black Spruce plots show a higher percentage of Moss Cover, but also a higher density.

These sites are frequently water-logged, for at least a part of the ycar, and it requires a further study of a number of Black Spruce sites in connection with the problem of Continuous Moss Cover to throw more light on the subject. A series of cut and uncut plots may help to understanding of the connection, if any, between moisture on the forest floor and the continuous moss cover, or even a study of uncut plots, and of contiguous plots destroyed by various agencies.

I think that it is plain that the density of Forest Canopy cover in Coniferous forests has a decided bearing on the continuous Moss Cover problem, but that density of deciduous trees (or at least of Poplars, the commonest deciduous species in the district examined) has no power to build up a continuous moss cover

Another point that I wish to establish is that instead of the Continuous Moss cover being an indicating agency, it is, on the contrary, a masking factor in connection with forest types.

If, as I suspect, Hylocomium splendens and parietinum bear each year a new single branch, we have traced these branches back 30 years, to find the stem still bearing fragments of branches. In other words, the mosses were perennials, and, like the Sphagnums, dying below, but continuing their growth above, so that, once established, there seems no reason why they should not continue to live indefinitely. Barring two disturbing factors, the letting in of light, from any cause, or a forest fire.

The list shows five cases of moss cover over $90 \%$, but this cover can be $100 \%$. I will refer to one case now, not referred to before because it was not plotted.

Near Sestinal Mountain, Highwood River, one of the valleys had a. steep rising slope, facing North. From the difficulty of climbing, and the necessity of using trees to help in the climbing, it must have been a rise of at least 45 degrees.

This had an $100 \%$ Moss Cover, a very deep cover, and in that cover it would be extremely difficult for any other plants to establish themselves. Other cases less extreme were frequently met with where the moss was so deep and so continuous that other species of plants would have very great difficulty in establishing themselves within it. 
These are not hypothetical cases, we frequently found cases where the plants were growing widely apart. I will refer to two..

Black Spruce Plot 2, continuous Moss Cover 96\%.

Cornus Canadensis (a stoloniferous plant of which each stem was counted as one plant) 1.10 feet apart. Petasites vitifolia 1.25 feet apart, Linnea Americana (of which each stem or rosette was counted as a single plant) 1.40 feet apart. Coptis trifoliata 3.15 feet apart. Vaccinium Vitis-idaea (of which each stem was counted as a single plant) 3.5 feet apart. Mitella nuda 4.5 feet apart. Cyanoccocus Canadensis 5.8 feet apart, the few other species ranging from 7 to 38 feet apart.

Any one conversant with forest conditions will know how thinly scattered this flora must have been, and the difficulty there must be in any species getting a foothold in such a moss cover. Yet less than a mile away a site that seemed similar, burnt over, with some years forest floor growth on it, seemingly an old Black Spruce site, had a much more frequent flora, though nearly all the same species were present.

In Black Spruce Plot 2 the thick moss had suppressed the other plant species so much that the frequencies were very different.

In Black Spruce Plot 1 the suppressed condition was even more marked. Continuous Moss cover $97 \%$, Cornus Canadensis 1.6 feet apart, Petasites vitifolia 2.8 feet apart, Coptis trofoliata 4.0 feet apart, and the very few other species from 4.5 to 20 feet apart. Yet an adjoining open space showed quite a well marked flora other than the continuous Moss type (note:-after Petasites vitifolia and Coptis trifoliata should come Linnea Americana 3.5 feet apart, Mitella nuda 3.5 feet apart).

The same lesson was learned from White Spruce plots of high moss cover percentage, that while the frequencies might range somewhat widely over the various forest canopy densities, and also of moss cover, it was invariably the case, as far as I can remember (for areas outside the plots were not often noted in the note books, or even different light conditions within the plot worked over, and their effect on the flora, were not noted in the journals, though noted at the time, and memorised) that open spots adjoining the plots of medium to high percentage of moss cover showed a much more frequent flora, a decidedly larger number of individuals, though not necessarily larger in species, or only to a slight degree. This was the more noticeable when, as occasionally happened, the light gap was within the plot being worked over.

In other words, it was where the moss cover was not dominant that the different species of plants grew best, while where the continuous moss cover was dominant the species of plants were present in altogether different quantities. The deep moss cover had acted as a masking agent or factor. To one working in the forests, this masking by the continuous moss cover of both fre- 
quencies of species (the most common form) and of species can be easily confirmed, after being pointed out.

From the above it follows that the Hylocomium or continuous moss eover is unsafe to use either as a forest type, or as part of a forest type, 1:-because it runs through a number of forest types without definite relation to any of them 2:- -because it has no definite relation to soil quality, 3:--because it masks the frequencies of the plants growing on sites occupied by the continuous moss cover.

We have got to depend upon other species of plants than the continuous moss cover to classify our forest types by.

There are other aspects of the continuous moss cover that require further study. Mention may be made of some of them.

It is not uncommon to talk of, and think of our forests as reservoirs or regulators of moisture, and the flow of water; without which we should have a series of floods and droughts.

There is evidence to support this statement, but it is not appreciated which constituent of the forest performs this useful function of regulation and storing.

It is not the trees, they alone would have but little power in that direction. It is the continuous moss cover which very largely performs this useful function acting as a sponge to take up heavy rainfalls, and releasing the moisture slowly to the soil below.

I have instanced a steep hillside near Sentinel Mountain covered by a very deep continuous layer of moss. It seemed to be little more than a mass of small rocks, and yet it carried a well stocked forest. As no tallies or sections were made it is not possible to say how highly it rated in the scale of timber values, but it is not difficult to conceive that if it faced South and was largely depleted of its moss cover it would be a much barer spot, carrying a much smaller timber volume.

The other side of that hill, facing South, was a more gradual slope, better supplied with soil, but carrying a sparse covering of tree growth, and comparatively little moss cover.

It will, I think, be readily conceded by anyone acquainted with this moss cover at, or near its best development that it has great capacities as a water reservoir under differing conditions of rainfall.

A secondary result of its capacity to hold moisture is a state of humidity in the forests not attainable where the rain soon runs off.

Quite frequently the slopes facing South carry Poplars, usually in a mixed forest, sometimes alone. Where this occurs, the falling leaves of the Poplars 
gradually form a laminated structure that tends rather to shed the rain than to conserve it.

This capacity of the continuous moss cover to hold moisture has possibilities in connection with soils eroded by run-off.

If it is possible to establish a coniferous forest growth, with a continuous moss cover to hold the moisture, there would be very little danger of erosion with anything less than a cloudburst or a tropical storm.

This moss cover acts also in another way.

The humus and small forest debris that would be washed away on a bare slope is held fast by the continuous moss, and gradually turned into plant food, thus building up and improving, very slowly and gradually, the forest site it covers.

There is room for intensive study of the deep moss in relation to forest sites, forest growth and forest rainfall and its conservation, a study that should richly repay any labour given to the subject, even the parts outlined seem to show that in a convincing manner.

Humidity, its connection with the moss of the forest floor, its relation to forest tree growth, of forest floor plant growth, its relation to soil values at least on less-than-saturated soils, how far and how closely it is related to the continuous moss on such soils, are all questions requiring further study, and will probably all be found closely bound up with the continuous moss problem.

\section{Appendix}

As Norralin's scale was found unsuited to our purpose, being too coarse, it became necessary to devise a scale that would suit us better.

Distances apart was tried but that was not found quite suitable, finally the plan of numbers per thousand feet was adopted, in corelation with the plan of 16 quadrats each two and an half feet square, which gave us 100 square feet. This allowed percentages to be used quite easily, and the consequent plotting often found desirable became both easy to make and easy to understand by those engaged or interested in this type of work. Percentages of mosses and other cryptogams also were simple.

As can be seen by reference to the scale, the greatest difference hetweert the bottom of one scale and the top of the next was as three to one. The Norralin scale gave irregular resuits, they are quoted as follows. Scale 2 to 3, plants 1 to 6 ; scale 3 to 4 , plants 1 to 4 ; scale 4 to 5 , plants as 1 to 4 ; scale 5 to 6 , plants as 1 to 9 ; scale 6 to 7 , plants as 1 to 36 . 
Table of Frequencies

\begin{tabular}{rrrrrrl}
\multicolumn{9}{c}{ Plants per 1000} & feet & \multicolumn{2}{c}{ Feet apart } & & Scale \\
1 & to & 4 & 34 & to & 17 & 1 \\
5 & to & 8 & 15.2 & to & 12.0 & 1.5 \\
9 & to & 12 & 11.3 & to & 9.9 & 2 \\
13 & to & 24 & 9.4 & to & 6.9 & 2.5 \\
25 & to & 36 & 6.8 & to & 5.65 & 3 \\
37 & to & 72 & 5.60 & to & 4.00 & 3.5 \\
73 & to & 108 & 3.95 & to & 3.25 & 4 \\
109 & to & 216 & 3.25 & to & 2.30 & 4.5 \\
217 & to & 324 & 2.30 & to & 1.90 & 5 \\
325 & to & 648 & 1.90 & to & 1.335 & 5.5 \\
649 & to & 972 & 1.33 & to & 1.09 & 6 \\
973 & to & 1944 & 1.09 & to & .77 & 6.5 \\
1945 & to & 2916 & .77 & to & .63 & 7 \\
2917 & to & 5832 & .63 & to & .445 & 7.5 \\
5833 & to & 8748 & .45 & to & .36 & 8 \\
8749 & to & 16496 & .36 & to & .26 & 8.5 \\
16497 & to & 26244 & .26 & to & .21 & 9 \\
26245 & to & 52488 & .21 & to & .17 & 9.5 \\
52489 & to & 78732 & .17 & to & .12 & 10
\end{tabular}

